\title{
Study on the Non-Contact FBG Vibration Sensor and Its Application
}

\author{
Tianliang LI, Yuegang TAN*, Zude ZHOU, Li CAI, Sai LIU, \\ Zhongting HE, and Kai ZHENG
}

Wuhan University of Technology, Wuhan, 430070, China
${ }^{*}$ Corresponding author: Yuegang TAN $\quad$ E-mail: ygtan@whut.edu.cn

\begin{abstract}
A non-contact vibration sensor based on the fiber Bragg grating (FBG) sensor has been presented, and it is used to monitor the vibration of rotating shaft. In the paper, we describe the principle of the sensor and make some experimental analyses. The analysis results show that the sensitivity and linearity of the sensor are $-1.5 \mathrm{pm} / \mu \mathrm{m}$ and $4.11 \%$ within a measuring range of $2 \mathrm{~mm}^{-}$ $2.6 \mathrm{~mm}$, respectively. When it is used to monitor the vibration of the rotating shaft, the analysis signals of vibration of the rotating shaft and the critical speed of rotation obtained are the same as that obtained from the eddy current sensor. It verifies that the sensor can be used for the non-contact measurement of vibration of the rotating shaft system and for fault monitoring and diagnosis of rotating machinery.
\end{abstract}

Keywords: Rotating shaft, FBG, non-contact, vibration sensor

Citation: Tianliang LI, Yuegang TAN, Zude ZHOU, Li CAI, Sai LIU, Zhongting HE, and Kai ZHENG, "Study on the Non-Contact FBG Vibration Sensor and Its Application," Photonic Sensors, 2015, 5(2): 128-136.

\section{Introduction}

Steam turbines, compressors, generators, and aviation engines are the principal rotating machinery. They play an important role in the development of the modern industrialized process. In addition, they are the basis equipments of some military and civilian sectors. Therefore, effective detection means can ensure their healthy and stable running. It's also an important strategic issue, which relates to the national economy and national security and defense.

Rotating machinery faults are often shown in vibration condition, which directly response to the health condition of the equipment, and they are important indicators of equipment safety assessments. Thus, the monitoring vibration signals are the principal means for rotating machinery condition monitoring and fault diagnosis [1]. Electrical sensors are often used for rotating shaft vibration measurement, such as the eddy-current sensor and inductive sensor. This kind of sensors has advantages of easy installation, high precision, long life, etc., but it is susceptible to electromagnetic interference (EMI) and lack of easy distributed measurement [2]. Compared with traditional sensors, fiber Bragg grating (FBG) sensors are anti-EMI, corrosion-resistant, high temperature, small volume, and light weight, and they are easy to conduct a long-distance transmission dynamic distributed measurement. Therefore, its applications are also attracting more and more attention, which are widely used in health monitoring, vibration measurement, and other areas [3-6]. Many scholars also designed some vibration sensors based on the

Received: 22 September 2014 / Revised version: 22 December 2014

(C) The Author(s) 2015. This article is published with open access at Springerlink.com

DOI: $10.1007 / \mathrm{s} 13320-015-0220-9$

Article type: Regular 
FBG, used the cantilever beam as elastic body, and pasted FBGs on the surface of the cantilever beam to measure vibration $[7,8]$; N. Basumallick et al. adjusted the distance between the FBG and neutral surface of the cantilever beam to increase the vibration sensor sensitivity [9]; Paulo Fernando da Costa Antunes et al. selected L-shaped beam as an elastomer, and mixed the mass on the end of beam which was supported by spring, and another end beam was connected with the FBG, to monitor structure vibration [10]; He Jun et al. used spring to convert the displacement of the measured body to force, which was imposed to the pasted FBG cantilever beam, to measure the displacement [11]; Yinyan Weng et al. also combined round diaphragm with L-shaped rigid beam to design a contact type of acceleration sensor for applications of structure health monitoring and earthquake monitoring [12]; some scholars used the flat diaphragm as the elastic body, added a mass in the center of flat diaphragm, through inertia force of mass caused the flat diaphragm deformation, and then made the FBG's central wavelength drift, to obtain vibration acceleration of the measured body [13]; literature $[14,15]$ proposed an FBG based on the non-contact magnetic coupling displacement sensor to achieve the non-contact measurement of the displacement of the objects.

Based on the above FBG vibration sensor, this paper presents a non-contact FBG vibration sensor. The FBG is fixed at both ends, which is contracted or expanded by the magnetic force. Then we can realize the vibration measurement by testing central wavelength shifts. In this paper, we make some theoretical and experimental analyses of the sensor, build a non-contact FBG vibration sensor experimental system and eddy current displacement sensor vibration measure system, and discuss the results. This paper describes the following aspects: principles and models of sensors, sensor calibration experiment, and multi-sensor vibration measuring experiment for the rotating shaft.

\section{Principle and model of non-contact FBG vibration sensor}

\subsection{Principle of FBG sensing}

The FBG is composed of periodic changes in the refractive index that are formed by the exposure to an intense UV interference pattern in the core of an optical fiber. When a broad band incident light comes into an FBG and meets the FBG, a particular wavelength narrow band light will be reflected, which is called the Bragg wavelength (Fig. 1). Also the wavelength of reflected light can be expressed as:

$$
\lambda_{B}=2 n \Lambda
$$

where $\lambda_{B}$ is the fiber Bragg grating wavelength, $n$ is the effective refractive index of the fiber core, and $A$ is the grating period.

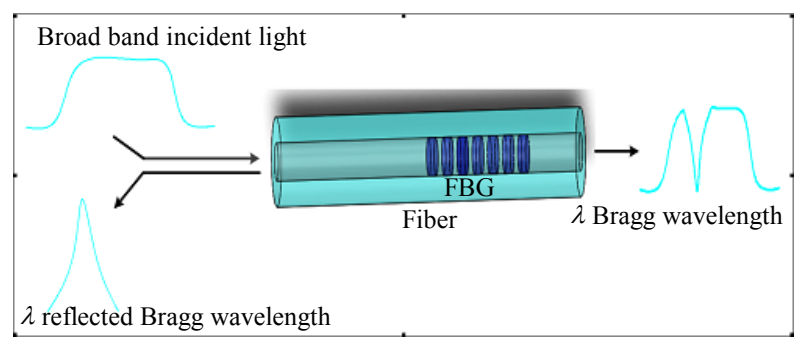

Fig. 1 Map of principle of FBG sensing.

According to (1), we can find that the reflection-FBG center wavelength is proportional to the grating period and the effective refractive index. When the FBG is interfered by extraneous factors, such as the FBG is stretched/compressed or the environment temperature changes, they will make the FBG's $A$ and $n$ change, and finally lead to the FBG's central wavelength shifts. So through the most basic physical theory of the FBG, it can be used to detect the corresponding physical quantities. In this paper, we ignore the effect of the temperature on the sensor, and the wavelength shift of FBG strain relation is as follows:

$$
\frac{\Delta \lambda_{B}}{\lambda_{B}}=1-P_{e}
$$

where $\Delta \lambda_{B}$ is the central wavelength shift, $\varepsilon$ is strain, and $P_{e}$ is the strain-optic coefficient of an optical fiber. 


\subsection{Working principle of the sensor}

The sensor equivalent structure model is shown in Fig. 2. Because the rotating shaft unbalance and other factors could excite the rotating shaft radial vibration, the distance between permanent magnets and the shaft to be measured would be changed which is called air gap spacing in this paper; according to the magnetic coupling of the permanent magnet and the measured magnetic shaft, the magnetic force is associated with the air gap spacing, so magnetic force which is exerted on the diaphragm, and deformation of diaphragm state are also changed. The FBG connected with the diaphragm is contracted or expanded by the magnetic force. Then the relevant shift of the central wavelength of the FBG occurs, finally we could attain vibration displacement of rotating shaft by the central wavelength of the FBG. According to the non-contact measure method, we have developed the non-contact FBG vibration sensor, which is shown in Fig. 3.

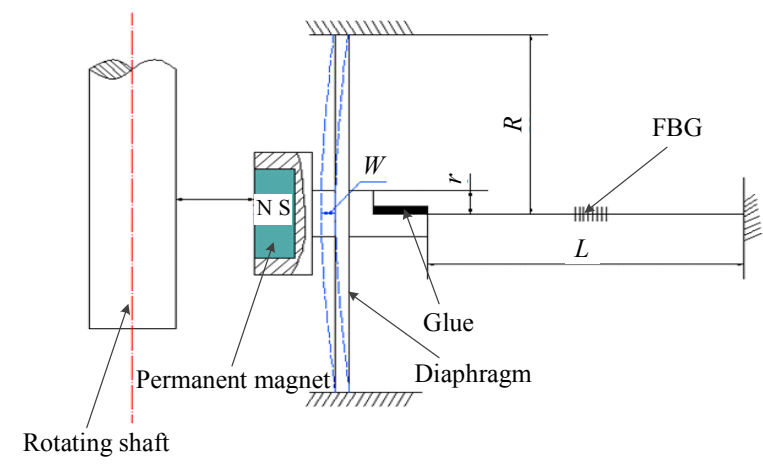

Fig. 2 Equivalent sensor structure model.

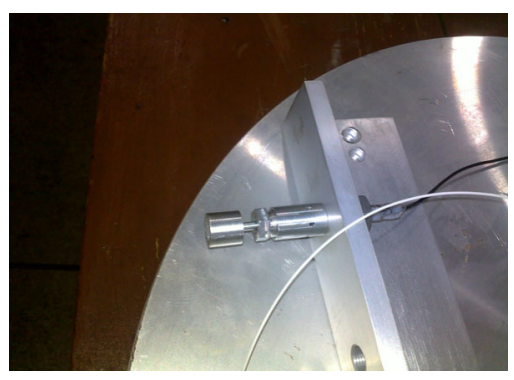

Fig. 3 Physical map of the sensor.

The working process of the sensor primarily consists of 3 physical converted processes: 1) the distance between the sensor and the shaft to be measured is converted into magnetic force; 2) the magnetic force which results in deformation of diaphragm, exerts on the diaphragm hardcore; 3 ) the deformation of diaphragm makes the central wavelength of the FBG change which is connected with the diaphragm. Due to the physical processes 1) and 2), we can get the relation between the bending deflection of the circumferential fixed circular diaphragm hard core under force and the magnetic force based on the theory of small deflection of elasticity and magneto mechanics theory, which is given by (3) [16]:

$$
W=\frac{F C}{\pi r^{2}\left(1+\frac{E_{f} A_{f} C}{\pi r^{2} L}\right)}
$$

where $E_{f}$ is Young's modulus of the optic fiber, $A_{f}$ means crosssectional area of the optic fiber, $L$ represents effective length of the FBG, $\mu$ represents the diaphragm Poisson ratio, $E$ is Young's modulus, $w$ is the bending deflection of diaphragm hardcore, $q$ is the distributed load, $h, R$, and $r$ are the diaphragm thickness, diaphragm radius, and diaphragm hardcore radius, respectively. When the sensor's material and size are determined, we can easily find that $\frac{3\left(1-\mu^{2}\right)}{16} \frac{R^{4}}{E \cdot h^{3}}\left(1-\frac{r^{4}}{R^{4}}+4 \frac{r^{2}}{R^{2}} \operatorname{In} \frac{r}{R}\right)$ is a constant. So we replaced it with $C$ to facilitate formula derivation.

Based on (2) and (3), we can obtain the relationship between the wavelength shift of the FBG and the air gap spacing in the process 3), and which is described by (4) [16]:

$$
=\left(1-P_{e}\right) \frac{\frac{\Delta \lambda}{\lambda}=\left(1-P_{e}\right) \quad \varepsilon=\left(1-P_{e}\right) \frac{w}{L}}{2 \mu_{0} \pi r^{2} L\left(1+\frac{E_{f} A_{f} C}{\pi r^{2} L}\right)\left(1+\frac{B_{r} L_{g}}{\mu_{0} L_{m} H_{c}}\right)^{2}}
$$

where $B_{r}$ and $H_{\mathrm{c}}$ are the permanent magnet remanence and coercivity, respectively, $\mu_{0}$ is the permeability of vacuum, $A_{g}$ is the cross-sectional area of air gap spacing, $L_{g}$ is the air gap spacing 
between the sensor and the measured body, and $L_{m}$ is the length of permanent magnet in the magnetization direction.

According to (4), we can ensure that the relationship between the central wavelength of the FBG and the air gap spacing is non-linear. To solve this problem, we use the liner processing and liner fitting method within small ranges, and eventually the vibrsation displacement can be measured by the FBG central wavelength shift.

\section{Calibration experiment of the sensor}

\subsection{Principle and setup of the experiment}

Any sensor could be calibrated before it is applied, so we did the research on its static characteristics of the sensor. In this paper, sensor's diaphragm size $R$ is $3 \mathrm{~mm}$, hard core radius $r$ is $1.5 \mathrm{~mm}$, and thickness $h$ is $0.05 \mathrm{~mm}$; N35 cylindrical neodymium-Iron-Boron permanent magnet diameter and length are $10 \mathrm{~mm}$.

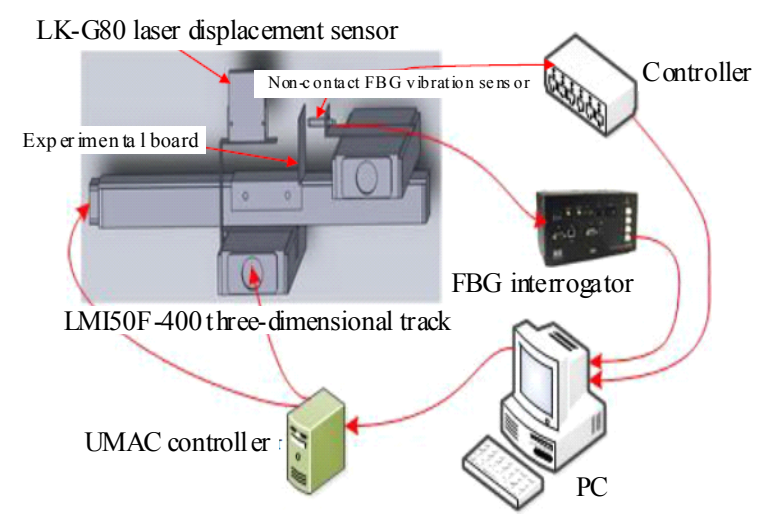

Fig. 4 Schematic map of the static experimental system.

We selects the LK-G80 laser displacement sensor (range: $30 \mathrm{~mm}$, zero point: $80 \mathrm{~mm}$, and resolution: $0.1 \mu \mathrm{m}$ ) as the experiment criterion to do the study on the static characteristics of the sensor. Also we use the laser displacement sensor as the non-contact FBG vibration sensor's reference. It is convenient for us to ensure the starting distance $L_{g 0}$ between the FBG sensor and the experimental board. We adjust the three-dimensional track to make the laser displacement sensor over against the experimental board's boss. $\Delta L_{g}$ can be ensured which is the variation of the distance between the laser displacement sensor and the fixed mount's boss, then we can achieve the current air gap spacing $L_{g}=L_{g 0}-\Delta L_{g}$. The schematic map of the static experiment system is shown in Fig. 4.

\subsection{Analysis of experimental results}

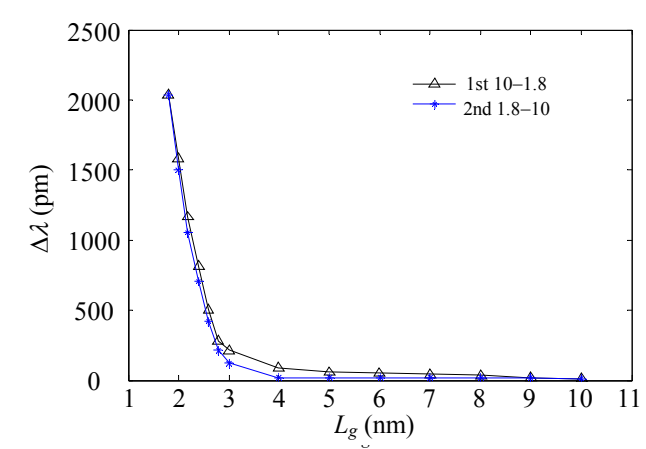

(a)

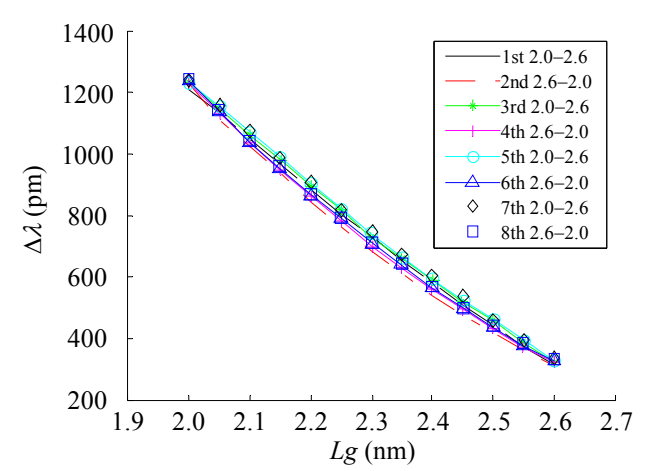

(b)

Fig. 5 Central wavelength drift versus air gap spacing: (a) relationship between the central wavelength shift and air gap spacing $2.0 \mathrm{~mm}-2.6 \mathrm{~mm}$ and (b) linear fitting curve.

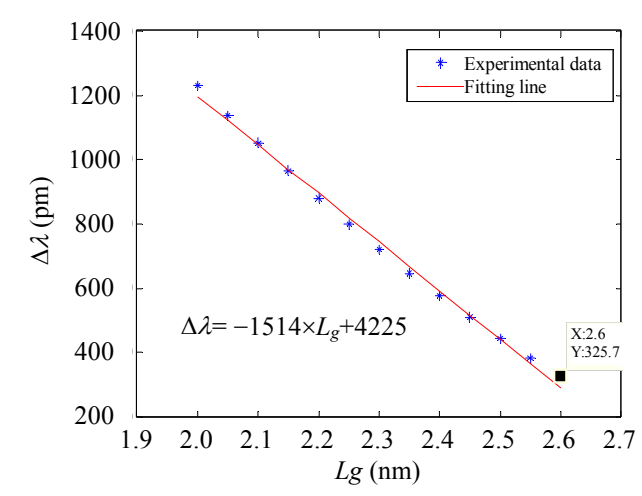

Fig. 6 Linear fitting curve.

During the experiment, we kept changing the air gap spacing within $1.8 \mathrm{~mm}-10 \mathrm{~mm}$ by adjusting the three-dimensional track and repeated the experiment 
2 times. The relation curve between the central wavelength of the FBG drift and the air gap spacing $L_{g}$ is shown in Fig. 5. It is shown that when the air gap spacing is within $1.9 \mathrm{~mm}-2.4 \mathrm{~mm}$, the sensor has better sensitivity as compared with that in other zones. So we selected the range of $2 \mathrm{~mm}-2.6 \mathrm{~mm}$ as the measurement range of the sensor. And the experiment has been repeated for 8 times. From Fig. 5(b), we can easily find that the repeatability error (the output values' misalignment level under the same strokes and full scale of sensor) is 3.58\%, and hysteresis error (the input-output curves misalignment level of sensors' positive and negative strokes) is $5.28 \%$. The average of 8 times experimental data of the sensor and the fitting straight line are shown in Fig. 6. From the fitting straight line, we can obtain the following data: 1) sensitivity: $-1.5 \mathrm{pm} / \mathrm{um}$, fitted equation: $\left.\Delta \lambda=-1514 \times L_{\mathrm{g}}+4225,2\right)$ linearity: $4.11 \%$, and 3 ) linear fitting correlation coefficient: 0.9952 , which are shown in Table 1.

Table 1 Parameters of non-contact FBG vibration sensor.

\begin{tabular}{cccc}
\hline Range $(\mathrm{mm})$ & 0.6 & Repeatability error (\%) & 3.58 \\
\hline Scope (mm) & $2-2.6$ & Hysteresis error (\%) & 5.28 \\
Linearity (\%) & 4.11 & Fitting line equation & $\Delta \lambda=-1514 \times L_{g}+4225$ \\
\hline
\end{tabular}

\section{Multiple-sensor vibration measurement of rotating shaft}

\subsection{Principle and setup of the experiment}

The experimental system schematic diagram and the physical map are shown in Fig. 7, which is mainly composed of the PC, frequency transformer, variable frequency motor, gearbox, rotating shaft, eddy current sensor (the mainly parameters are shown in Table2), non-contact FBG vibration sensor (central wavelength: $1315.6245 \mathrm{~nm}$ ), NI-DAQ cards, FBG interrogator, etc. We selected the wheel disc as the measured subject, so the eddy current displacement sensor and non-contact FBG vibration sensor were symmetrically installed on the both sides of wheel disc. We could get different speeds of variable-frequency motor by adjusting the control box and then collected the vibration signal at different speeds with the two sensor measure systems.

Before the experiment, we ensured the zero point of the eddy current sensor (the midpoint of the range: $1.58 \mathrm{~mm}$, corresponds to value of current: $12 \mathrm{~mA}$ ) and non-contact FBG vibration sensor (the midpoint of the range: $2.3 \mathrm{~mm}$, corresponds to the central wavelength shift: $742.8 \mathrm{pm}$ ) by fitting the line of each other. In order to get the zero points, we adjusted the distance between the sensor and wheel disc by the screw micrometer which was fixed behind the sensor [Fig. 7(b)]. In this experiment, the eddy current displacement sensor and non-contact FBG vibration sensor's points were $2.329 \mathrm{~mm}$ and $1.484 \mathrm{~mm}$, respectively.

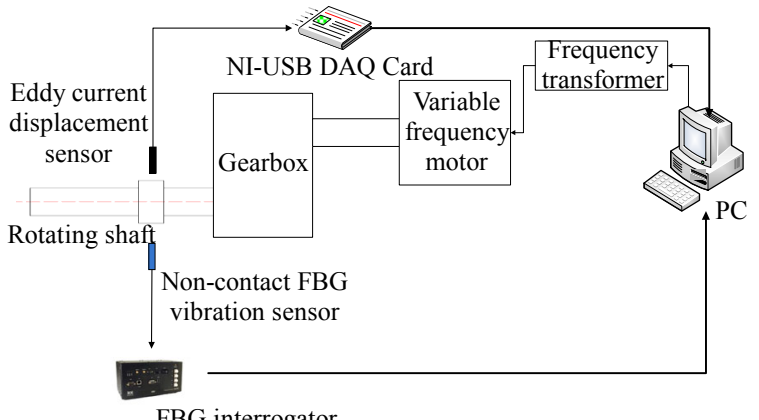

(a)

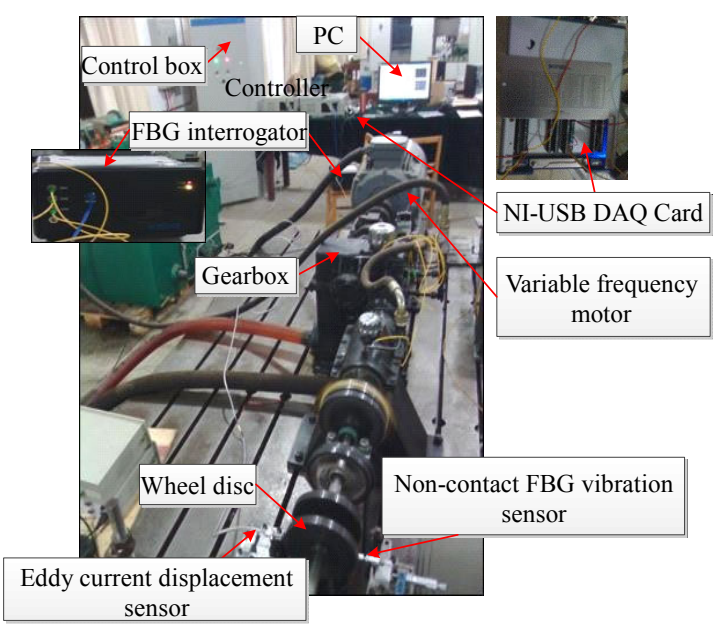

(b)

Fig. 7 Schematic diagram and physical map of the multiple-sensor vibration measurement system: (a) schematic diagram of multiple-sensor vibration measurement system, and (b) physical map of the multiple-sensor vibration measurement system.

During the experiment, we first made the wheel disc at a certain speed and then acquired vibration 
signals by the Lab VIEW acquisition system (Fig. 8) and FBG demodulation system. We have repeated the experiment at different constant speeds (300 r/min, $480 \mathrm{r} / \mathrm{min}, \quad 660 \mathrm{r} / \mathrm{min}, 840 \mathrm{r} / \mathrm{min}$, $1020 \mathrm{r} / \mathrm{min}, 1200 \mathrm{r} / \mathrm{min}, 1380 \mathrm{r} / \mathrm{min}, 1560 \mathrm{r} / \mathrm{min}$, $1740 \mathrm{r} / \mathrm{min}, 1920 \mathrm{r} / \mathrm{min}, 2100 \mathrm{r} / \mathrm{min}, 2280 \mathrm{r} / \mathrm{min}$, and $2460 \mathrm{r} / \mathrm{min}$ ) through adjusting the speed of the rotating shaft.

Table 2 Parameters of the eddy current displace sensor.

\begin{tabular}{ll}
\hline Type of parameter & \multicolumn{1}{c}{ Value of parameters } \\
\hline Power supply & $+24 \mathrm{~V}$ \\
Temperature & $25^{\circ} \mathrm{C}$ \\
Range & $0.58 \mathrm{~mm}-2.58 \mathrm{~mm}$ \\
Neutral of range & $1.58 \mathrm{~mm}$ \\
Sensitivity & $8.00 \mathrm{~mA} / \mathrm{mm}$ \\
Linearity & $0.7 \%$ \\
Fitting line & $I=7.980 \times D-0.534 ;$ : current $(\mathrm{mA})$ \\
& $D:$ distance between the sensor and the measured $(\mathrm{mm})$ \\
\hline
\end{tabular}

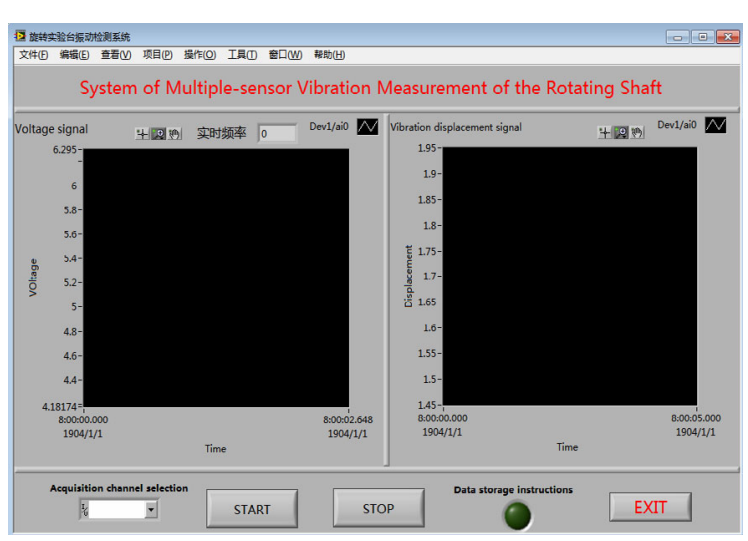

Fig. 8 Upper computer acquisition system of the eddy current displacement sensor.

\subsection{Results and discussion}

(1) The time domain and Spectrum of the vibration signal

In order to conveniently compare with eddy current sensor's analysis, we took the zero point of two sensors as $0 \mu \mathrm{m}$ in the diagram. The vibration displacement time domain graphs are shown in Fig. 9 at the speed of $300 \mathrm{r} / \mathrm{min}, 480 \mathrm{r} / \mathrm{min}$, $2100 \mathrm{r} / \mathrm{min}$, and $2280 \mathrm{r} / \mathrm{min}$.

We used the fast Fourier transform algorithm (FFT) to dispose the vibration signals of the two sensors, and the spectrum charts of $300 \mathrm{r} / \mathrm{min}$, $480 \mathrm{r} / \mathrm{min}, 2100 \mathrm{r} / \mathrm{min}$, and $2280 \mathrm{r} / \mathrm{min}$ are shown in Fig. 10.
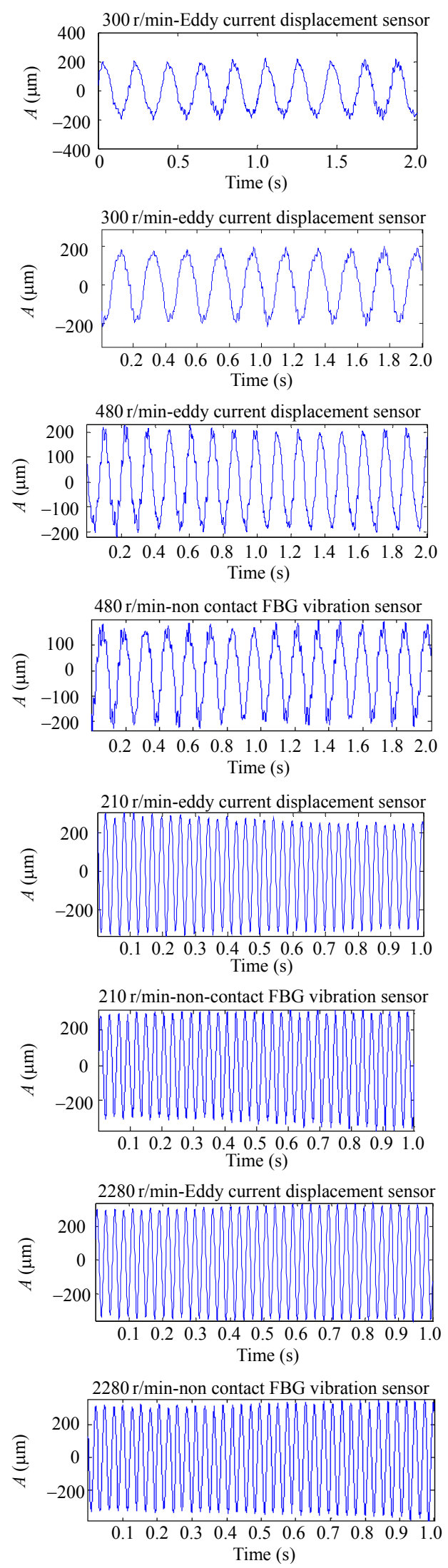

Fig. 9 Vibration displacement time domain of the two sensors. 

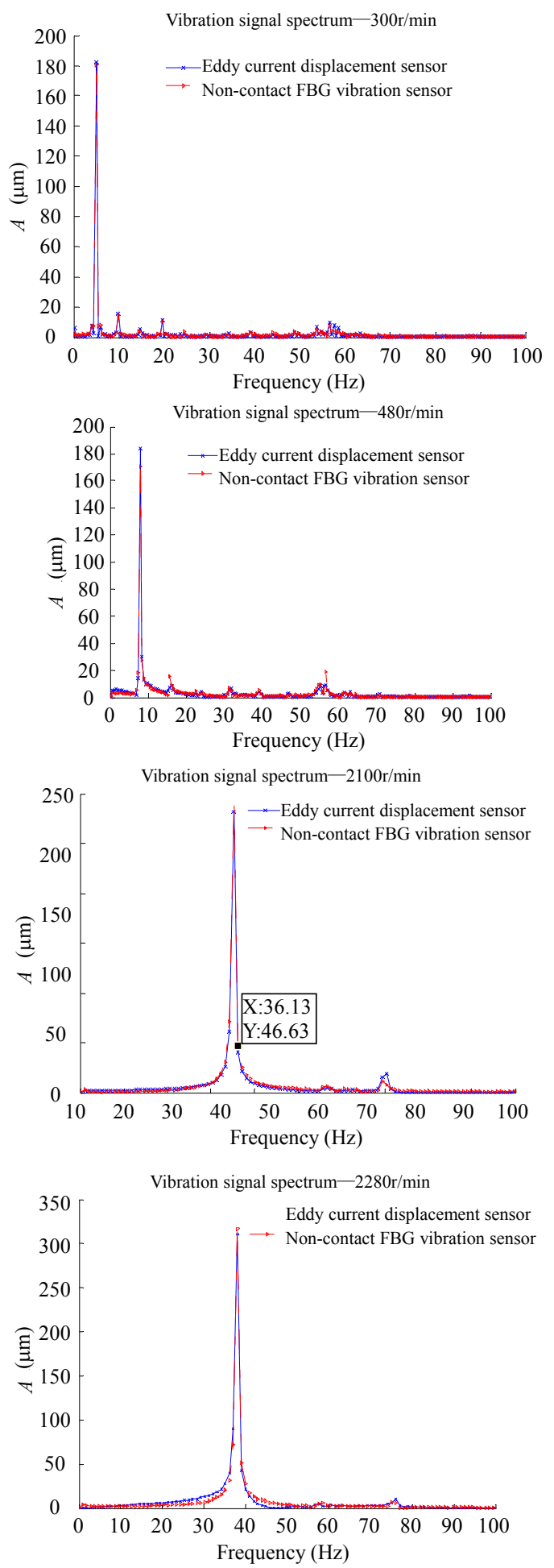

Fig. 10 Spectrum of the two sensors' vibration signal.

From Figs. 9 and 10, we can find that the time domain signals of the two sensors are almost the same and both of them are approximately sine signals, which is consistent with the real vibration situation of wheel disc. And the spectra of the two sensors' signals are basic overlapping, but there are still some differences. So we did further analysis of the two sensors' vibration displacement within the $1 \times$ frequency, and $2 \times$ frequency, and the results are shown in Table 3.

Table 3 Vibration displacement of the two sensors at the $1 \times$ and $2 \times$ frequency.

\begin{tabular}{ccccccc} 
Parameters & $\begin{array}{c}\text { Eddy current } \\
\text { displacement } \\
\text { sensor }\end{array}$ & \multicolumn{2}{c}{$\begin{array}{c}\text { Non-contact } \\
\text { FBG vibration } \\
\text { sensor }\end{array}$} & \multicolumn{2}{c}{$\begin{array}{c}\text { Relative } \\
\text { error }\end{array}$} \\
\hline 300 & 364.8 & 31.1 & 361.2 & 28.0 & -1.0 & -10.0 \\
480 & 368.4 & 16.5 & 341.8 & 30.2 & -7.2 & 83.0 \\
660 & 340.0 & 17.2 & 402 & 36.5 & 18.2 & 112.2 \\
840 & 396.2 & 23.1 & 384.8 & 32.0 & -2.9 & 38.5 \\
1020 & 350.4 & 31.1 & 367.8 & 50.6 & 5.0 & 62.7 \\
1200 & 359.4 & 55.6 & 401.8 & 76.1 & 11.8 & 36.9 \\
1380 & 426.4 & 32.9 & 419.8 & 30.9 & -1.5 & -6.1 \\
1560 & 460.6 & 85.8 & 456.8 & 122.1 & -0.8 & 42.3 \\
1740 & 425 & 426.8 & 464.6 & 674 & 9.3 & 57.9 \\
1920 & 423.6 & 80.2 & 420.4 & 72.0 & -0.8 & -10.2 \\
2100 & 564.2 & 39.1 & 588 & 24.3 & 4.2 & -37.9 \\
2280 & 622 & 21.4 & 623.6 & 14.3 & 0.3 & -33.2 \\
2460 & 638.8 & 16.6 & 672.6 & 26.6 & 5.3 & 60.2 \\
\hline
\end{tabular}

From Table 2, we can find that the relative error of P-P value is within $10 \%$ except at speeds of $660 \mathrm{r} / \mathrm{min}$ and $1200 \mathrm{r} / \mathrm{min}$ in $1 \times$ frequency. But there is a large difference of the P-P values between the eddy current and non-contact FBG vibration at the $2 \times$ frequency, also the value of the non-contact FBG sensor is always bigger than the eddy current. It is shown that it is more sensitive to high-frequency component and may be caused by itself structure. We could do the further research on the sensor, and optimize its dynamic performance in the future.

From the above analysis, the tendency of the two sensors' signals are the same, which demonstrate that the non-contact FBG vibration sensor can be applied to measure the vibration of rotating shaft, but the accuracy and reliability of FBG vibration sensor need to be further improved.

(2) Critical speed analysis

It's vitally significant to ensure the critical speed, because it can help us to avoid the rotating shaft working at a critical speed. We could extract the critical speed from the multiple-sensor signal, and 
the diagram of the P-P value of vibration displacement versus the speed is shown in Fig. 11. From the figure, we can easily find that: 1) the tendency and value of the critical speed which are extracted by FBG vibration sensor are consistent with the eddy current displacement sensor; 2) when the speed is less than $1600 \mathrm{r} / \mathrm{min}$, the P-P value is almost the same; 3) when the speed equals to $1800 \mathrm{r} / \mathrm{min}$, there is a resonance phenomenon, and its vibration P-P value appears to severely change and reach maximum; 4) seen from the line with triangle of Fig. 11, the absolute difference P-P value of the two sensors fluctuates near the zero. Also it is shown that the signal of non-contact FBG vibration sensor is credibility.

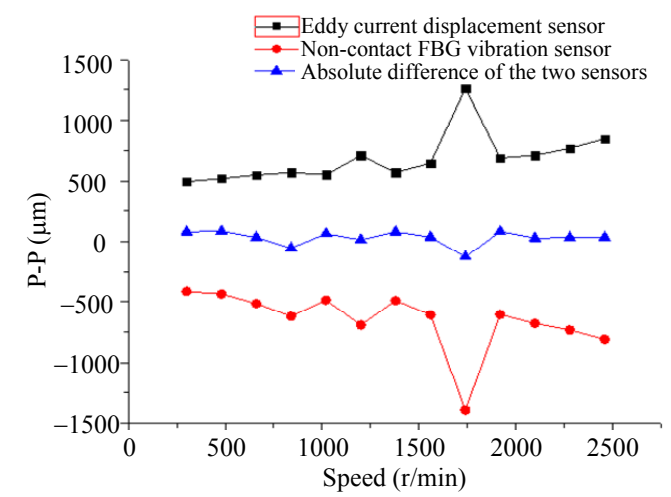

Fig. 11 P-P value of the vibration displacement versus the speed.

\section{Conclusions}

This paper presents a non-contact vibration sensor based on the FBG and applied to measure the rotating shaft vibration. Experimental results show relevant data of the sensor are: 1) measurement range: $2 \mathrm{~mm}-2.6 \mathrm{~mm}$; 2) sensitivity: $-1.5 \mathrm{pm} / \mu \mathrm{m}$; 3) linearity: $4.11 \%$; 4) linear regression correlation coefficient: $0.9952 ; 5)$ repeatability error: $3.58 \%$; 6) hysteresis error: $5.28 \%$. We built two vibration measurement systems based on the eddy current displacement sensor and non-contact FBG vibration sensor. We can find: 1) the results show the performance of the FBG vibration sensor are consistent with eddy current displacement sensor, which verified the credibility of the FBG sensor that it can effectively detect the vibration of the rotating shaft; 2) some parameters still are different, and we could do the further research on the sensor's performance to improve its performance. According to the requirements of monitoring rotating shaft vibration, we can improve the non-contact FBG vibration sensor to achieve the different requirements. Also we can use the FBG's wavelength division multiplexing technology to achieve a multi- parameter detection system with other FBG sensors.

\section{Acknowledgment}

This work was supported by a grant from the National High Technology Research and Development Program of China (863 Program) (No. 2012AA040106).

Open Access This article is distributed under the terms of the Creative Commons Attribution License which permits any use, distribution, and reproduction in any medium, provided the original author(s) and source are credited.

\section{References}

[1] X. Zhou, "Research on purification/feature extraction and automatic identification of axis orbit of rotating machinery," M.S. thesis, Chongqing University, Chongqing, China, 2010.

[2] Y. Qin, X. Meng, and R. Sun, “The application of the eddy current transducer in condition monitoring and fault diagnosing system for rotating machinery," in 2011 International Conference on Information, Services and Management Engineering (ISME2011), Beijing, China, pp. 1532-1535, 2011.

[3] B. Lee, "Review of the present status of optical fiber sensors," Optical Fiber Technology, 2003, 9(2): $57-59$.

[4] K. O. Hill and G. Meltz, "Fiber Bragg grating technology fundamentals and overview," Journal of Lightwave Technology, 1997, 15(8): 1263-1276.

[5] D. Jiang and W. He, "Review of applications for fiber Bragg grating sensors," Journal of Optoelectronics Laser, 2002, 13(4): 420-430.

[6] W. Li, J. Liu, J. Pan, J. Pang, and X. Lu, "FBG stress-sensibilized monitor for railway switch pole on-line monitoring," Photonic Sensors, 2014, 4(3): 269-273. 
[7] J. Zhang, Y. Xiong, and A. Yang, "Study of FBG application in acceleration sensing," in IEEE 9th International Conference on Properties and Applications of Dielectric Materials, Harbin, China, July 19-23, 2009.

[8] W. Zhou, X. Dong, C. Shen, C. Zhao, C. Chan, and P. Shum, "Temperature-independent vibration sensor with a fiber Bragg grating," Microwave and Optical Technology Letters, 2010, 52(10): 2282-2285.

[9] N. Basumallick, I. Chatterjee, P. Biswas, K. Dasgupta, and S. Bandyopadhyay, "Fiber Bragg grating accelerometer with enhanced sensitivity," Sensors and Actuators A: Physical, 2012, 173(1): 108-115.

[10] P. F. D. C. Antunes, H. F. T. Lima, N. J. Alberto, H. Rodrigues, P. M. F. Pinto, J. D. L. Pinto, et al., "Optical fiber accelerometer system for structural dynamic monitoring," IEEE Sensors Journal, 2009, 9(11): 1347-1354.

[11] J. He, H. Dong, Z. Zhou, and G. Zhang, "A kind of new displacement sensor based on FBG for engineering," Journal of Harbin University of
Science and Technology, 2010, 15(5): 61-64.

[12] Y. Weng, X. Qiao, Z. Feng, M. Hu, J. Zhang, and Y. Yang, "Compact FBG diaphragm accelerometer based on L-shaped rigid cantilever beam," Chinese Optics Letters, 2011, 9(10): 22-25.

[13] Q. Liu, X. Qiao, J. Zhao, Z. Jia, H. Gao, and M. Shao, "Novel fiber Bragg grating accelerometer based on diaphragm," IEEE Sensors Journal, 2012, 12(10): 3000-3004.

[14] J. Wang, B. Liu, F. Zhang, and D. Jiang, "Non-contact magnetic coupling fiber Bragg grating displacement sensor," Nanotechnology and Precision Engineering, 2008, 6(6): 468-472.

[15] H. Mi and Q. Nan, "Study on magnetic coupling FBG displacement sensor," in 2011 IEEE International Conference on Mechatronics and Automation August, Beijing, pp. 2443-2447, 2011.

[16] T. Li, Y. Tan, L. Wei, Z. Zhou, K. Zheng, and Y. Guo, "A non-contact fiber Bragg grating vibration sensor," Review of Scientific Instruments, 2014, 85(1): 015002. 